\title{
Surgical treatment of chronic papilloedema in children
}

\author{
F. A. BILLSON AND R. L. HUDSON \\ Royal Children's Hospital, Melbourne
}

The treatment of progressive loss of vision that results from chronic papilloedema through raised intracranial pressure can be one of the most difficult problems facing the clinician, particularly when the underlying condition is not readily amenable to conventional neurosurgery.

A surgical approach via the orbit to incise the optic nerve sheath to relieve papilloedema and preserve vision has a history that dates back to the igth century. There has been renewed interest in this local surgical treatment of patients with chronic papilloedema since Davidson (1969) presented the results of his work in patients with papilloedema due to inoperable cerebral tumours.

De Wecker (1872) approached the optic nerve sheath by a transconjunctival approach between the lateral and inferior rectus muscles $1 \mathrm{~cm}$. from the limbus. He went via Tenon's space and used a spatula to luxate the globe up and medially. He then used a specially-designed neurotome to feel and then incise the sheath in an antero-posterior direction and he tried to include the edge of the posterior scleral canal at the entrance of the optic nerve. He had no direct view, and the pupil disturbance he described suggests interference with the posterior ciliary nerves.

Carter (I887a,b; 1889) had reservations about De Wecker's technique, and after dissecting a cadaver, he used a lateral conjunctival approach in which he disinserted the lateral rectus muscle and approached the optic nerve sheath via Tenon's space. He had a direct view of the sheath and he used a sharp pointed knife and a hook to incise the sheath for about 1 inch. The posterior scleral canal was not incised.

Müller (I916) used a Krönlein orbitotomy for his approach. Davidson (r 969 ) used a Berke modification of Krönlein's lateral orbitotomy and approached the nerve sheath above the lateral rectus muscle; he described difficulty in defining the nerve sheath. $\mathrm{He}$ incised in an antero-posterior direction $\mathrm{I} \mathrm{cm}$. behind the globe on the supero-lateral aspect, in order to avoid the central retinal vessels.

An approach via the medial side of the globe after first performing lateral orbitotomy was described by Smith, Hoyt, and Newton (I969). The lateral orbitotomy allowed retraction of the eyeball laterally. Address for reprints: F. A. Billson, D.O., F.R.C.S., F.R.A.C.S., Royal Children's Hospital, Flemington Road, Parkville, 3052, Victoria, Australia
In 1972 at the $4^{\text {th }}$ Asio-Pacific Congress of Ophthalmology, Galbraith (1973) described his approach along the medial side of the globe using a trachael dilator for adequate exposure; and at the same meeting Billson (1973) drew attention to optic nerve sheath surgery in children, also approaching the optic nerve sheath from the medial side.

The purpose of this paper is three-fold:

(I) To give details of a surgical technique used to approach the optic nerve sheath in children.

(2) To show the documented effect of incision of the optic nerve sheath on resolution of chronic disc oedema in a case of otitic hydrocephalus and one of craniostenosis.

(3) To emphasize that this surgery failed to control the intracranial pressure but still resulted in resolution of disc oedema and restoration of optic nerve function.

\section{Operative technique}

Surgery is done under general anaesthesia with relaxants and the operating microscope is used during the final approach to the optic nerve sheath.

A limbal approach to Tenon's space is made by conjunctival and Tenon's incision over $270^{\circ}$ (Fig. I). The insertion of the medial rectus muscle is exposed and two 6/o catgut sutures are placed through the edges of the muscle which is then disinserted. A silk traction suture is passed through the stump of the insertion and is used to lift the globe forwards and laterally. Copper spatulas help to retract the medial rectus and Tenon's capsule away from the globe and to prevent orbital fat obscuring the operative field. As the dissection is carried posteriorly, the microscope is introduced and the line of the long posterior ciliary vessels is estimated, this leads to the posterior ciliary vessels and nerves which are readily identified closely connected with the greyish bulging optic nerve sheath (Fig. 2).

With Bond's forceps, the sheath is picked up and with either a razor blade segment or Vannas scissors, an elliptical or triangular segment of the sheath is removed, to reveal a flow of cerebrospinal fluid. The medial rectus is then reattached, and the conjunctiva closed with $6 / 0$ plain catgut. 

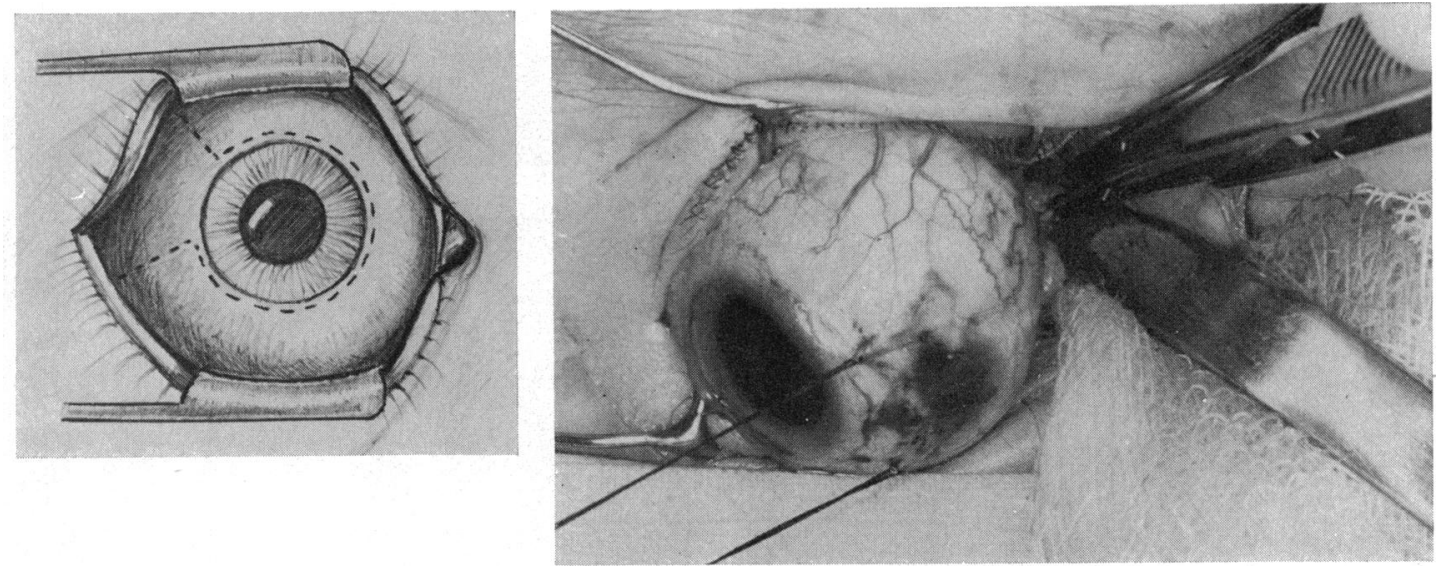

FIG. I Case I, right eye, showing extent of limbal incision. Radial incisions are used as illustrated

FIG. 2 General view of the procedure. The forceps are pointing to the right optic nerve

\section{Case reports}

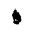

Gase I, an II-year-old girl, was admitted to hospital with a 2-week history of diplopia and headaches after otitis interna and mastoiditis.

\section{Examination}

There was bilateral sixth nerve palsy and papilloedema (Figs 3 and 4). The visual acuity was $6 / 9$ in each eye and the visual fields were normal.

Lumbar puncture at this time showed a cerebrospinal

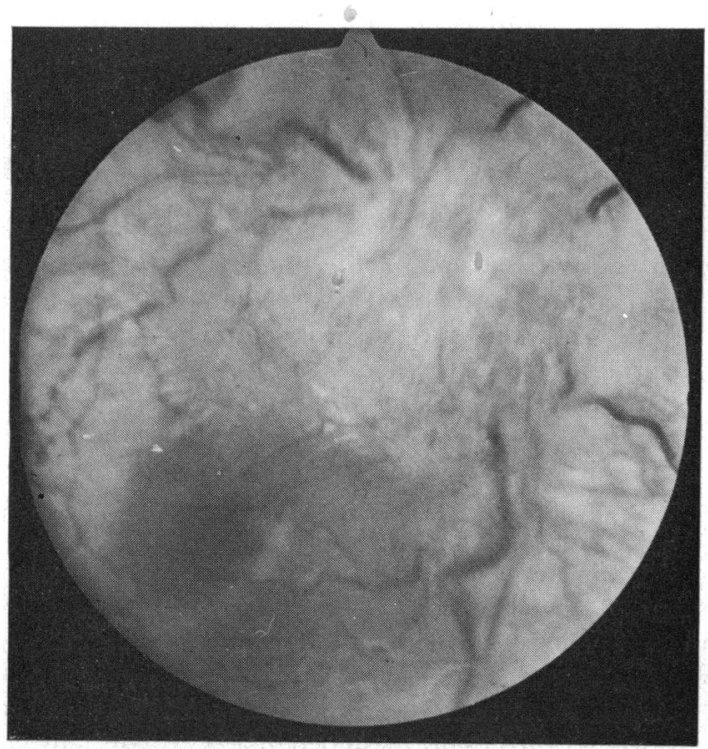

fluid pressure of $340 \mathrm{~mm}$. Carotid angiography showed a thrombosis of the lateral sinus. A Myodil ventriculogram was reported as normal. One month later the vision had deteriorated to $6 / 12$ in each eye, the visual fields had become constricted, and she complained of visual obscurations.

\section{Operation}

A bilateral optic nerve decompression via the medial approach was carried out after consultation with the neurosurgeons and neurologists.

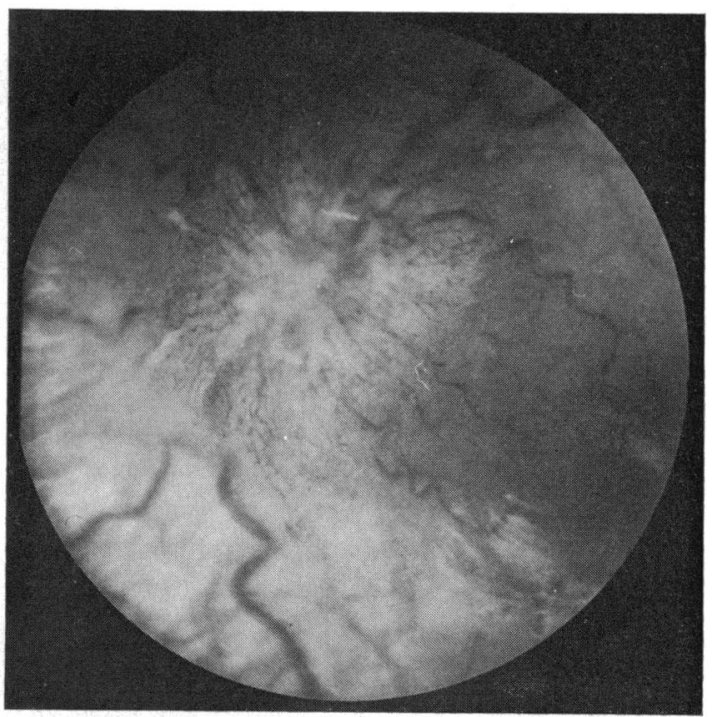


FIGS 5 and 6 Case I, showing marked resolution of oedema postoperatively with decrease in vessel tortuosity

\section{Result}

I week later the visual acuity was still $6 / 12$ in each eye, but she had full binocular vision and had no further symptoms. After 2 weeks the disc oedema was much less, and 3 weeks postoperatively the visual acuity was 6/6 and the discs showed striking resolution (Figs 5 and 6). The visual fields had also returned to normal. A repeat lumbar puncture at this time showed that the CSF pressure was still in the range of $340 \mathrm{~mm}$. Within 3 months the optic discs were flat.

Case 2, a baby girl, had been noted at birth to have features of Apert's syndrome, At 5 months of age she underwent a conventional bilateral coronal suture splitting procedure for craniostenosis. At 3 years of age perverted ocular movements and bilateral disc oedema was noted. The disc oedema was observed for 3 months and it was then decided, in consultation with neurosurgeons, that optic nerve decompression should be undertaken because of the known risk of failing vision in children with craniostenosis.

\section{Operation}

An optic nerve sheath decompression was performed on the right side with the above technique by removing a $1 \times 3$ $\mathrm{mm}$. segment of sheath from the medial side.

\section{Result}

4 days postoperatively the disc oedema on the right side was noted to be much less; 2 weeks postoperatively the swelling had resolved even further but the left optic nerve head remained swollen; 2 months postoperatively, the right disc was flat and the left still oedematous.

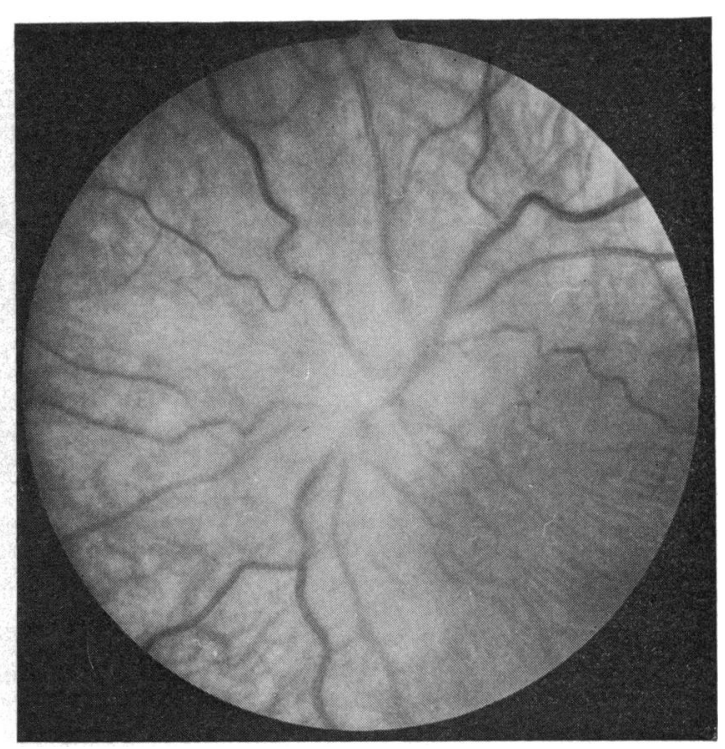

\section{Second operation}

Further neurosurgery was then performed because the child was showing continued delay in development. After extensive linear craniotomy and craniectomy the left disc oedema subsided.

Result

At the last report the optic discs had remained flat and the visual acuity was recorded as $6 / 18$ in both eyes.

\section{Discussion}

The need to consider ocular surgery to relieve longstanding papilloedema depends on documented evidence of progressive loss of visual function in those patients with reasonable life prognosis in whom it has been decided not to perform neurosurgery. The decision for this surgery is best undertaken in joint consultation with the neurologists and neurosurgeons.

In cases of benign intracranial hypertension (pseudotumour cerebri) the above indications may be fulfilled. Profound visual loss with consequent permanent blindness may occur in cases of neglected pseudotumour cerebri (Smith, 1958).

Craniostenosis with chronic papilloedema needs careful consideration if the neurologists and neurosurgeons are satisfied with the general development of the child. Matson (1969) drew attention to the problem of papilloedema with multiple cranial suture closure. The papilloedema is usually chronic without haemorrhages and is due to increasing intra- 
cranial pressure as brain growth proceeds. Optic atrophy eventually occurs if the condition is neglected and blindness may result.

The response to surgery of the optic nerve sheath in children with papilloedema confirmed clinically the experimental findings of Hayreh (1964, 1968). In Case I resolution of disc oedema followed operations on the optic nerve sheaths. In Case 2 the disc oedema diminished on the side where an optic nerve sheath decompression was performed, and subsequently a craniotomy and suture splitting operation relieved the disc oedema on the other side. In Case I, when lumbar puncture was performed some weeks after the operation, at a time when the disc oedema was subsiding (cf. Figs 3 and 4 with 5 and 6), the cerebrospinal fluid pressure was at the same level after operation as before

The evidence suggests that, by opening the optic nerve sheath, only local factors inherent in the production of papilloedema are altered. It must therefore be emphasized that optic nerve sheath decompression should be reserved solely for cases in which visual function appears endangered, and should not be performed for the control or relief of raised intracranial pressure. The mechanism by which local factors are altered is not understood. Davidson
(1969, 1970) reported two cases in which he had obtained post mortem specimens after his operations. He found that in both cases the gap produced by the surgery was filled in by fibroblastic tissue. His explanation for the response was attributed to blocking of the vaginal space by this fibroblastic tissue, thereby protecting the optic nerve head from the raised cerebrospinal fluid pressure. Using radioactive isotope introduced into the cerebrospinal fluid, it was not possible to demonstrate leakage of cerebrospinal fluid via the optic nerve sheath (in Case I); however, more refined isotope techniques may provide further information as to the mode of action of optic nerve sheath decompression.

\section{Summary}

A surgical technique for optic nerve decompression in children is described and contrasted with other techniques described in the literature.

The operation was effective in relieving longstanding disc oedema in two cases in which the swelling was due to raised intracranial pressure. Photographic evidence is presented.

The indications for surgery and how its effect is exerted are discussed.

\section{References}

BILlson, F. A. (I973) Trans. ophthal. Soc. N.Z., 25, 169

CARTer, R. B. (1887a) Proc. med. Soc. Lond., I0, 290

(1887b) Brain, ro, 199

(1889) Brit. med. J., 1, 399

DAvidson, s. I. (1969) Trans. ophthal. Soc. U.K., 89, 669

(1972) In "The Optic Nerve", p. I 74, ed. J. s. CANT. Kimpton, London

DE WEGKER, L. (1872) "4th Ophthalmological Congress, London", p. I I

GAlbRAith, J. E. K. (1973) Trans. ophthal. Soc. N.Z., 25, 165

HAYREH, s. S. (1964) Brit. F. Ophthal., 48, 522

- (1968) Docum. ophthal., 24, 289

MATSON, D. D. (1969) "Neurosurgery of Infancy and Childhood", 2nd ed., p. I 3o. Thomas, Springfield, Ill.

MülleR, L. (I9I6) Wien. klin. Wschr., 29, I OOI

Smith, J. L. (I958) Trans. Amer. Acad. Ophthal., Otolaryng., 62, 432

-, HOYт, w. F., and Newton, т. H. (I969) Amer. 7. Ophthal., 68, 633 